\title{
STRATEGI PENGELOLAAN PASAR IKAN MODERN DI PELABUHAN PERIKANAN SAMUDERA NIZAM ZACHMAN JAKARTA
}

\author{
Modern Fish Market Management Strategies at Nizam Zachman Jakarta Ocean Fishing Port
}

Oleh:

\author{
Iin Solihin ${ }^{1}$, Ni Ketut Leni Meilani², Retno Muninggar ${ }^{3}$ \\ ${ }^{1}$ Departemen Pemanfaatan Sumberdaya Perikanan,Institut Pertanian Bogor.iin_solihin@apps.ipb.ac.id \\ 2 Program Studi Teknologi dan Manajemen Perikanan Tangkap, Institut Pertanian Bogor. lenimeilaniarsana@gmail.com \\ 3Departemen Pemanfaatan Sumberdaya Perikanan Institut Pertanian Bogor.muninggar@apps.ipb.ac.id
}

*Korespondensi: iin_solihin@apps.ipb.ac.id

Diterima: 25 Februari 2021; Disetujui: 1 April 2021

\begin{abstract}
Modern Fish Market (MFM) is the result of relocation from the Fish Marketing Center (FMC) located at the Nizam Zachman Ocean Fisheries Port in Jakarta (NZOFPJ). The relocation of the market has caused traders to protest against the manager. One of their actions is to go on a fish payment strike, which affects the stability MFM cash flow. Accordingly, the management needs to investigate the financial condition of MFM to determine future actions for the market sustainability. However, no study has been conducted regarding the financial condition of MFM. This study aims to determine the comparison of MFM and FMC revenue and strategies to improve the existing situation. A case study was conducted in the Nizam Zachman Fishing Port in Jakarta. Financial data of MFM and FMC including problems encountered by MFM were collected from the business division of Perum Perindo Jakarta, MFM management team and MFM traders. Revenue analysis, SWOT analysis as well as Quantitative Strategic Planning Matrix were perfomed in this study. The results showed that revenue generated by the MFM was IDR 1,474,085,972.00, which is lower than the FMC revenue (IDR 2,360,855,000.00). In order to improve MFM financial situation, nine strategies have been formulated and primarily it has been focused on the development of small and medium enterprises.
\end{abstract}

Keywords: : revenue, management, modern fish market, NZOFPJ, strategy.

\section{ABSTRAK}

Pasar Ikan Modern (PIM) merupakan hasil relokasi dari Pusat Pemasaran Ikan (PPI) yang berlokasi di Pelabuhan Perikanan Samudera Nizam Zachman Jakarta (PPSNZ). Perelokasian pasar menyebabkan pedagang melakukan aksi protes kepada pengelola. Salah satunya adalah banyak pedagang melakukan aksi mogok bayar, sehingga berpengaruh terhadap pendapatan pengelola PIM. Pihak pengelola perlu mengetahui kondisi pendapatan PIM untuk menentukan tindakan ke depan bagi keberlanjutan PIM. Namun, hingga saat ini belum ada kajian mengenai kondisi pendapatan PIM. Penelitian ini bertujuan mengetahui perbandingan pendapatan PIM dan PPI dan menyusun strategi untuk meningkatkan pendapatan PIM. Penelitian ini dilakukan di Pelabuhan Perikanan Samudera Nizam Zachman Jakarta menggunakan metode studi kasus. Data pendapatan PIM dan PPI serta permasalahan pengelolaan PIM diperoleh dari Divisi Usaha Perum Perindo Cabang Jakarta, Divisi Manajemen pengelola PIM, dan pedagang PIM. Data dianalisis menggunakan analisis pendapatan, analisis SWOT dan Quantitative Strategic Planning Matrix. Hasil penelitian menunjukkan bahwa pendapatan PIM sebesar Rp1.474.085.972,00 lebih rendah 
dibandingkan pendapatan PPI sebesar Rp2.360.855.000,00. Terdapat sembilan strategi yang direkomendasikan untuk meningkatkan pendapatan PIM dengan prioritas strategi utama yaitu pengembangan usaha kecil dan menengah.

Kata kunci: pasar ikan modern, pendapatan, pengelolaan, PPSZJ, strategi

\section{PENDAHULUAN}

Pelabuhan perikanan merupakan prasarana penting dalam pengembangan perikanan khususnya perikanan tangkap (Wahyu et al. 2019) dan sekaligus penggerak pertumbuhan ekonomi masyarakat (Rahmawati et al. 2014). Pelabuhan perikanan mempunyai berbagai fungsi, diantaranya adalah fungsi pemasaran hasil perikanan. Fungsi pemasaran pelabuhan perikanan ini dapat mencakup ketersediaan fasilitas, pelayanan dan ketersediaan sistem informasi (Putri et al. 2017).

Kesadaran masyarakat akan pentingnya mutu ikan yang baik saat ini mengalami peningkatan. Mutu ikan yang baik dapat meningkatkan kepercayaan konsumen dan menstabilkan harga (Afiyah et al. 2019). Seiring dengan tuntutan masyarakat terhadap produk yang sehat dan higienis, maka pengembangan pasar ikan di pelabuhan perikanan diarahkan menjadi pasar ikan modern (PIM) yang mengusung konsep bersih, higienis dan modern. Salah satu pasar ikan modern yang dikembangkan di Indonesia berlokasi di Pelabuhan Perikanan Samudera (PPS) Nizam Zachman Jakarta. Pasar ini merupakan hasil perelokasian dari Pusat Pemasaran Ikan (PPI). Keberadaan PIM, diharapkan dapat menghilangkan stigma masyarakat terhadap pasar ikan yang kurang higienis dan kotor. Pemerintah juga berharap adanya konsep baru mengenai pasar ikan tidak hanya bertujuan memindahkan PPI ke pasar yang lebih modern, namun dapat meningkatkan daya tarik minat konsumen dari berbagai kalangan termasuk wisatawan, sehingga dapat meningkatkan pendapatan pedagang maupun pengelola.

Berdasarkan Surat Keputusan Direktur Jenderal Penguatan Daya Saing Produk Kelautan dan Perikanan No. 130/KEP-DJPDSPKP/2018 tentang Penugasan kepada Perusahaan Umum Perikanan Indonesia sebagai Pengelola Sementara Operasionalisasi PIM Muara Baru Jakarta, menyatakan bahwa Perum
Perindo ditunjuk sebagai pengelola sementara operasionalisasi PIM Muara Baru Jakarta di bawah Divisi Manajemen Pengelola PIM. Perum Perindo sendiri merupakan Badan Usaha Milik Negara (BUMN) yang dibentuk berdasarkan Peraturan Pemerintah no. 9 tahun 2013 tentang Perum Perikanan Indonesia. Menurut Revitasari (2017), pengelolaan pasar merupakan proses pengaturan kegiatan perdagangan yang berlangsung di pasar dengan sumber daya meliputi pedagang, tempat usaha, dan pengorganisasiannya. Pengelolaan yang tepat terhadap PIM dapat berpengaruh terhadap pendapatan yang diterima oleh pengelola, yaitu divisi manajemen pengelola PIM.

Pihak pengelola menargetkan pendapatan yang dihasilkan dari PIM akan meningkat dari pasar sebelumnya. Perubahan pasar yang telah dilakukan dan tersedianya fasilitas yang memadai sangat mendukung peningkatan pendapatan yang akan dihasilkan. Berdasarkan hasil survei yang telah dilakukan, perelokasian pasar tidak serta membuat para pedagang merasa senang. Semenjak berdirinya PIM banyak pedagang yang melakukan aksi protesnya kepada pengelola, baik terkait dengan fasilitas yang disediakan maupun harga. Salah satu aksi protes tersebut diwujudkan oleh para pedagang dengan melakukan aksi mogok bayar, sehingga berpengaruh terhadap pendapatan yang dihasilkan oleh pengelola. Pihak pengelola perlu melakukan evaluasi terhadap kondisi pendapatan PIM agar dapat menentukan tindakan yang harus dilakukan kedepan untuk keberlanjutan PIM. Namun, hingga saat ini belum ada kajian mengenai bagaimana kondisi pendapatan PIM setelah direlokasinya PPI menjadi PIM. Perelokasian pasar yang terjadi tidak selalu mengakibatkan peningkatan pendapatan. Kebijakan mengenai perelokasian pasar dapat menyebabkan pendapatan pedagang menurun (Manzanaris et al. 2018; Endrawanti dan Wahyuningsih 2014). Ada tiga kemungkinan yang dapat terjadi dalam proses perelokasian PPI menjadi PIM, yaitu terjadi penurunan pendapatan, pening- 
katan pendapatan dan tidak terjadi penurunan maupun peningkatan pendapatan. Oleh sebab itu, sangat diperlukan penyusunan strategi pengelolaan pasar yang tepat untuk meningkatkan pendapatan PIM.

Penelitian penelitian yang terkait dengan pemasaran ikan di PPS Nizam Zachman Jakarta, diantaranya dilakukan oleh Najah et al. (2015),

Berdasarkan permasalahan diatas, hingga saat ini belum ada informasi mengenai bagaimana kondisi pendapatan pihak pengelola setelah dipindahkannya PPI ke PIM. Oleh karena itu kajian ini dilakukan untuk mengetahui perbandingan pendapatan PPI dan PIM serta merumuskan strategi pengelolaan pasar yang tepat agar dapat meningkatkan pendapatan PIM.

\section{METODE}

Pengambilan data dilakukan di Pelabuhan Perikanan Nizam Zachman Jakarta pada bulan yaitu Januari-Februari 2020 dengan menggunakan metode studi kasus. Data yang dikumpulkan adalah data penerimaan dan pengeluaran PPI (sebelum direlokasi) dari bulan Maret 2018 - Januari 2019 dan data penerimaan dan pengeluaran PIM (setelah direlokasi) dari bulan Maret 2019 - Januari 2020. Data tersebut digunakan untuk menghitung perbandingan pendapatan PIM dan PPI. Analisis perbandingan pendapatan PIM dan PPI dilakukan di tahun yang berbeda dengan asumsi kondisi perekonomian di tahun-tahun tersebut relatif tidak mengalami perubahan. Pendapatan PIM/PPI diperoleh dengan menggunakan rumus:

$\pi=T R-T C$

dengan

$$
\begin{array}{ll}
\pi & : \text { Pendapatan usaha PIM/PPI (Rp) } \\
\text { TR } & : \text { Total penerimaan (Rp) } \\
\text { TC } & : \text { Total biaya (Rp) }
\end{array}
$$

Penerimaan usaha merupakan hasil yang didapatkan selama periode penjualan satu tahun dirumuskan menjadi:

$T R=Q \times P$

dengan:

$$
\begin{array}{ll}
\text { TR } & \text { : Total penerimaan PIM/PPI (Rp) } \\
\mathrm{Q} & : \text { Kuantitas } \\
\mathrm{P} & : \text { Harga/jasa fasilitas PIM/PPI (Rp) }
\end{array}
$$

Biaya total merupakan penjumlahan dari seluruh biaya operasional yang terdiri dari biaya tetap dan biaya variabel dirumuskan menjadi:

$T C=T F C+T V C$

dengan :

TC : Total biaya (Rp)

TFC : Total biaya tetap (Rp)

TVC : Total biaya variabel $(\mathrm{Rp})$

Hasil analisis menghasilkan besaran pendapatan yang diterima oleh pengelola PIM dan PPI setiap bulannya dalam satu tahun. Kriteria yang digunakan untuk mempresentasikan besaran pendapatan adalah sebagai berikut:

$$
\begin{aligned}
& \pi P I M>\pi P P I \\
& \pi P I M<\pi P P I \\
& \pi P I M=\pi P P I
\end{aligned}
$$

Selain itu, digali juga informasi terkait dengan berbagai faktor internal dan eksternal dalam pengelolaan PIM tersebut. Pemilihan responden dilakukan dengan quota sampling, yaitu pengambilan jumlah sampel yang telah dijatah dari setiap sub kelompoknya (Siyoto dan Sari 2016). Alasan penggunaan quota sampling karena jumlah populasi yang terlalu kecil (Wagiran 2013). Proses wawancara dilakukan terhadap divisi manajemen pengelola PIM, divisi usaha PPI, dan pedagang PIM. Jumlah sampel yang diambil dalam penelitian ini adalah $10 \%$ dari jumlah populasi. Menurut Umar (2008), penelitian yang bersifat deskriptif, maka sampel minimumnya $10 \%$ dari populasi. Responden yang diambil dari masing-masing sub populasi yaitu divisi usaha PPI (2 orang), manajemen pengelola PIM (5 orang), pemilik kios (10 orang) dan pedagang PIM (31 orang). Pedagang PIM tersebut merupakan pedagang yang sama saat di PPI. Total responden yang diambil adalah 48 orang.

Perumusan strategi dilakukan dengan menggunakan analisis SWOT (Strength Weakness Opportunities Threaths). Analisis SWOT ini digunakan untuk menyusun faktor-faktor strategis perusahaan yang terdiri dari faktor internal (kekuatan dan kelemahan) dan faktor eksternal (ancaman dan peluang) (Nazwirman dan Wulandari 2016; Rangkuti 2018).

Analisis lanjutannnya adalah menggunakan Quantitative Strategic Plannning Matrix (QSPM) yang merupakan teknik yang secara objektif dapat menetapkan 
strategi alternatif yang diprioritaskan (Setyorini et al. (2016). Komponen utama dari QSPM adalah Key Factors, Strategic Alternatives, Weights, Attractiveness Score (AS), Total Attractiveness Score (TAS), dan Sum Total Attractiveness Score (STAS).

\section{HASIL}

\section{Pendapatan Pasar Ikan Modern}

Penerimaan PIM diperoleh dari jasa jasa yang diberikan yaitu pengadaan air tawar, air asin, sewa lapak, kios dan foodcourt, perolehan awal sewa, perpanjangan sewa, dan pemindahan hak sewa/ganti nama. Sedangkan pengeluaran merupakan biaya yang dikeluarkan untuk pembayaran air asin dan air tawar, gaji karyawan, listrik dan internet. Rincian penerimaan, pengeluaran dan pendapatan yang diperoleh pengelola PIM di Pelabuhan Nizam Zachman Jakarta disajikan pada Tabel 1.

Berdasarkan Tabel 1, terlihat bahwa pendapatan terbesar terjadi pada bulan Desember 2019 sebesar Rp194.287.169,00 dan pendapatan terkecil terjadi pada bulan Maret 2019 sebesar Rp69.468.820,00. Total Penerimaan, pengeluaran dan pendapatan PIM berturutturut adalah Rp5.042.013.156,00; Rp3.658.215.184,00.

Rp1.474.085.972,00.

\section{Pendapatan Pusat Pemasaran Ikan}

Penerimaan PPI diperoleh dari sewa lapak dan kios, perolehan awal sewa, perpanjangan sewa, pemindahan hak sewa/ganti nama,gudang, depot es dan tempat pengepakan ikan. Sedangkan pengeluaran merupakan biaya pembayaran gaji karya- wan dan listrik. Rincian penerimaan, pengeluaran dan pendapatan pengelola PPI di Pelabuhan Nizam Zachman Jakarta disajikan pada Tabel 2.

$$
\begin{aligned}
& \text { Pendapatan terbesar terjadi pada } \\
& \text { bulan Januari } 2019 \text { sebesar } \\
& \text { Rp218.750.000,00 dan pendapatan } \\
& \text { terkecil terjadi pada bulan Juni } 2018 \\
& \text { sebesar Rp211.850.000,00. Total } \\
& \text { penerimaan, pengeluaran dan pendapatan } \\
& \text { PPI berturut-turut adalah } \\
& \text { Rp2.662.255.000,00, Rp301.400.000,00 } \\
& \text { dan } R p 2.360 .855 .000,00 \text {. }
\end{aligned}
$$

\section{Perbandingan Pendapatan PIM dan PPI}

Perbandingan pendapatan antara PIM dan PPI disajikan pada Gambar 1. Gambar 1 menunjukkan bahwa pendapatan PIM lebih kecil dibandingkan dengan PPI. Hal ini disebabkan total pengeluaran PIM lebih besar jika dibandingkan dengan pengeluaran PPI. Pengelolaan air bersih dan air tawar yang diambil alih oleh PIM yang kemudian didistribusikan ke pedagang menyebabkan meningkatnya pengeluaran. Pihak pengelola melakukan pembelian air bersih di Water Supply dan air asin di Koperasi Samudera Jaya dan menjualnya kembali kepada para pedagang. Selain itu, harga sewa lapak yang meningkat hampir empat kali lipat dari harga lapak sebelumnya serta pembayaran air yang mahal membuat para pedagang banyak yang menunggak untuk membayar, sehingga menyebabkan piutang PIM semakin meningkat dan penerimaan menjadi tidak maksimal. Hal ini berbeda dengan pada saat PPI dimana para pedagang mampu memenuhi pembayaran fasilitas yang disediakan pengelola dan jumlah pengeluaran yang dihasilkan PPI cenderung lebih kecil.

Tabel 1 Pendapatan Pasar Ikan Modern selama bulan Maret 2019 - Januari 2020

\begin{tabular}{lrrr}
\hline \multicolumn{1}{c}{ Bulan } & Penerimaan (Rp) & Pengeluaran (Rp) & \multicolumn{1}{c}{ Pendapatan (Rp) } \\
\hline Maret & $472.414 .496,00$ & $402.945 .676,00$ & $69.468 .820,00$ \\
April & $435.293 .646,00$ & $324.989 .676,00$ & $110.303 .970,00$ \\
Mei & $440.495 .506,00$ & $318.994 .476,00$ & $121.501 .030,00$ \\
Juni & $436.701 .168,00$ & $294.531 .188,00$ & $142.169 .980,00$ \\
Juli & $499.288 .896,00$ & $389.984 .950,00$ & $109.303 .946,00$ \\
Agustus & $427.358 .810,00$ & $239.208 .360,00$ & $188.150 .450,00$ \\
September & $450.642 .797,00$ & $301.837 .648,00$ & $148.805 .149,00$ \\
Oktober & $441.197 .996,00$ & $298.859 .675,00$ & $142.338 .321,00$ \\
November & $460.894 .606,00$ & $332.517 .546,00$ & $141.516 .757,00$ \\
Desember & $576.406 .715,00$ & $382.119 .546,00$ & $194.287 .169,00$ \\
Januari & $491.606 .520,00$ & $385.366 .140,00$ & $106.240 .380,00$ \\
\hline Total & $\mathbf{5 . 0 4 2 . 0 1 3 . 1 5 6 , 0 0}$ & $\mathbf{3 . 6 5 8 . 2 1 5 . 1 8 4 , 0 0}$ & $\mathbf{1 . 4 7 4 . 0 8 5 . 9 7 2 , 0 0}$ \\
\hline
\end{tabular}


Tabel 2 Pendapatan Pusat Pemasaran Ikan selama bulan Maret 2018- Januari 2019

\begin{tabular}{lccc}
\hline Bulan & Penerimaan (Rp) & Pengeluaran (Rp) & Pendapatan (Rp) \\
\hline Maret & $254.250 .000,00$ & $27.400 .000,00$ & $217.850 .000,00$ \\
April & $243.750 .000,00$ & $27.400 .000,00$ & $216.350 .000,00$ \\
Mei & $240.105 .000,00$ & $27.400 .000,00$ & $212.705 .000,00$ \\
Juni & $239.250 .000,00$ & $27.400 .000,00$ & $211.850 .000,00$ \\
Juli & $244.350 .000,00$ & $27.400 .000,00$ & $216.950 .000,00$ \\
Agustus & $239.850 .000,00$ & $27.400 .000,00$ & $212.450 .000,00$ \\
September & $241.950 .500,00$ & $27.400 .000,00$ & $212.550 .000,00$ \\
Oktober & $240.800 .000,00$ & $27.400 .000,00$ & $213.400 .000,00$ \\
November & $241.250 .500,00$ & $27.400 .000,00$ & $213.850 .000,00$ \\
Desember & $239.550 .000,00$ & $27.400 .000,00$ & $212.150 .000,00$ \\
Januari & $246.150 .000,00$ & $27.400 .000,00$ & $218.750 .000,00$ \\
\hline Total & $\mathbf{2 . 6 6 2 . 2 5 5 . 0 0 0 , 0 0}$ & $\mathbf{3 0 1 . 4 0 0 . 0 0 0 , 0 0}$ & $\mathbf{2 . 3 6 0 . 8 5 5 . 0 0 0 , 0 0}$ \\
\hline
\end{tabular}

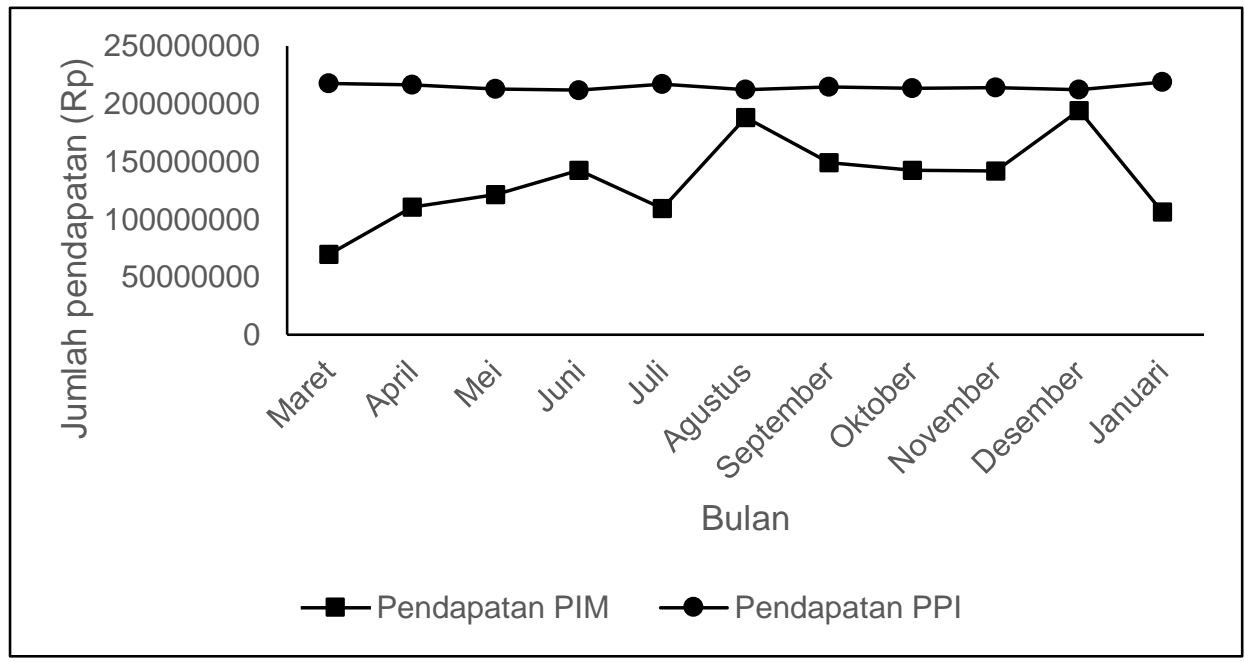

Gambar 1 Perbandingan pendapatan PIM dan PPI (Maret 2019-Januari 2020)

\section{Strategi Pengelolaan Pasar untuk Meningkatkan Pendapatan PIM}

Meski saat ini pendapatan PIM masih di bawah pendapatan PPI, namun di masa yang akan datang mempunyai peluang pengembangan yang relatif besar. Hal ini disebabkan konsep pengembangan PIM ini mengusung konsep yang modern dan wisata kuliner perikanan yang memang sesuai dengan kecenderungan masyarakat saat ini apalagi berada di ibukota negara dengan tingkat permintaan terhadap produk perikanan yang higienis cenderung mengalami peningkatan. Perancangan strategi perlu dilakukan untuk dapat meningkatkan serta menarik minat konsumen dari berbagai kalangan, baik untuk melakukan aktivitas jual beli maupun menikmati wisata kuliner perikanan.

Faktor faktor internal yang dimiliki PIM merupakan modal dasar yang dapat digunakan untuk meraih peluang dan mengurangi ancaman usaha pasar ikan ini.
Faktor faktor internal dan eksternal serta strategi yang diperlukan tersebut adalah seperti yang disajikan pada Gambar 2.

Analisis QSPM yang menentukan strategi prioritas dalam peningkatan pendapatan PIM menghasilkan formasi strategi sebagaimana disajikan pada Tabel 3. Urutan rekomendasi strategi diperoleh dari nilai STAS terbesar hingga yang terkecil. Urutan rekomendasi strategi adalah sebagai berikut : (1) pengembangan usaha kecil dan menengah (UKM) (2) membangun kerjasama dengan youtuber dan selebgram dalam mempromosikan PIM, (3) memberikan sistem angsuran dalam proses pembayaran lapak dan fasilitas yang digunakan para pedagang, (4) menciptakan sistem online market untuk dapat menjangkau konsumen dari berbagai wilayah di Indonesia, (5) penambahan area pembongkaran ikan yang nyaman, bersih dan mudah dijangkau oleh pedagang maupun konsumen, (6) dalan system pembayaan konsumen kepada pedagang penambahan kar- 
yawan dan peningkatan pemantauan terhadap ketersediaan fasilitas PIM, (7) meningkatkan spesialisasi kerja karyawan dan pemantauan terhadap ketersediaan fasilitas PIM, (8) meningkatkan ciri khasPIM, (9) melakukan koordinasi dan meningkatkan komunikasi antara pengelola PIM dan PPI, sesama pengelola PIM serta antara pengelola PIM dengan pedagang. Analisis QSPM merupakan analisis lanjutan dari analisis SWOT untuk menentukan strategi prioritas yang dihasilkan dari matriks SWOT. Hasil dari analisis QSPM dapat dijadikan pedoman untuk pengelola PIM dalam pengelolaan pasar untuk meningkatkan pendapatan PIM.

\section{PEMBAHASAN}

Pelabuhan perikanan berdasarkan Permen KP No 8/2012 tentang Kepelabuhanan Perikanan merupakan tempat yang terdiri atas daratan dan perairan di sekitarnya dengan batas-batas tertentu sebagai tempat kegiatan pemerintahan dan kegiatan sistem bisnis perikanan yang digunakansebagai tempat kapal perikanan bersandar, berlabuh, dan/atau bongkar muat ikan yang dilengkapi dengan fasilitas keselamatan pelayaran dan kegiatanpenunjang perikanan. Pelabuhan perikanan ini mempunyai fungsi pemerintahan dan fungsi pengusahaan (Sam et al. 2011). Oleh karena itu, disamping memberikan pelayanan umum kepada para penggunanya, pelabuhan perikanan juga diharapkan mampu membangkitkan aktifitas ekonomi yang berdampak pada peningkatan pendapatan penggunanya dan juga pendapatan pengelola pelabuhan perikanannya. Salah satu fungsi pengusahaan di pelabuhan perikanan tersebut adalah sebagai pusat pemasaran hasil perikanan. Hal ini dimungkinkan karena adanya interaksi nelayan sebagai penjual dan para pedagang sebagai pembeli. Keberhasilan aktifitas di pelabuhan perikanan termasuk di dalamnya aktifitas pemasaran harus didukung oleh ketersediaan sarana dan prasarana pelabuhan perikanan (Nurdyana et al. 2013).

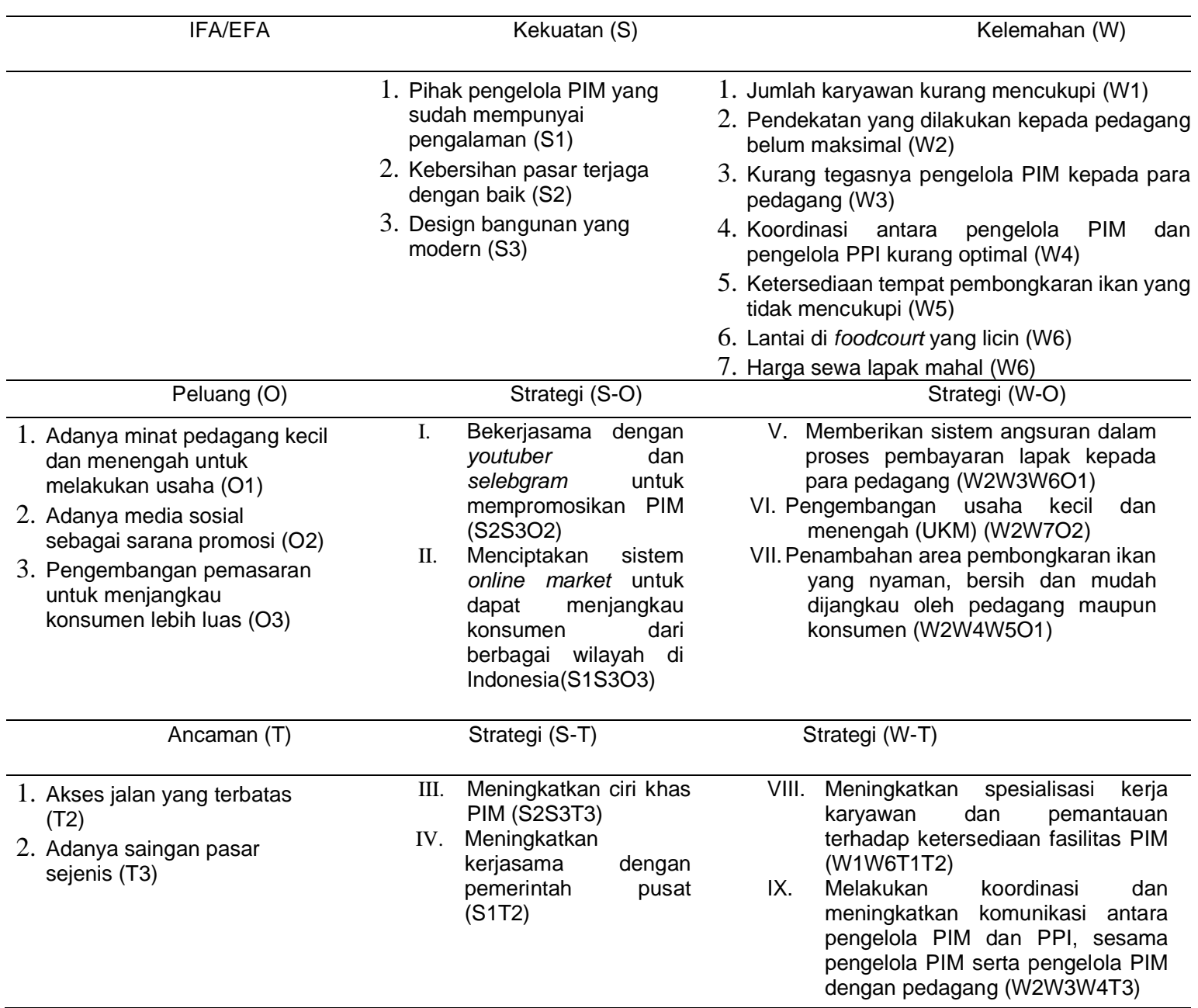


Tabel 3 Hasil perhitungan QSPM terkait prioritas strategi peningkatan pengelolaan PIM

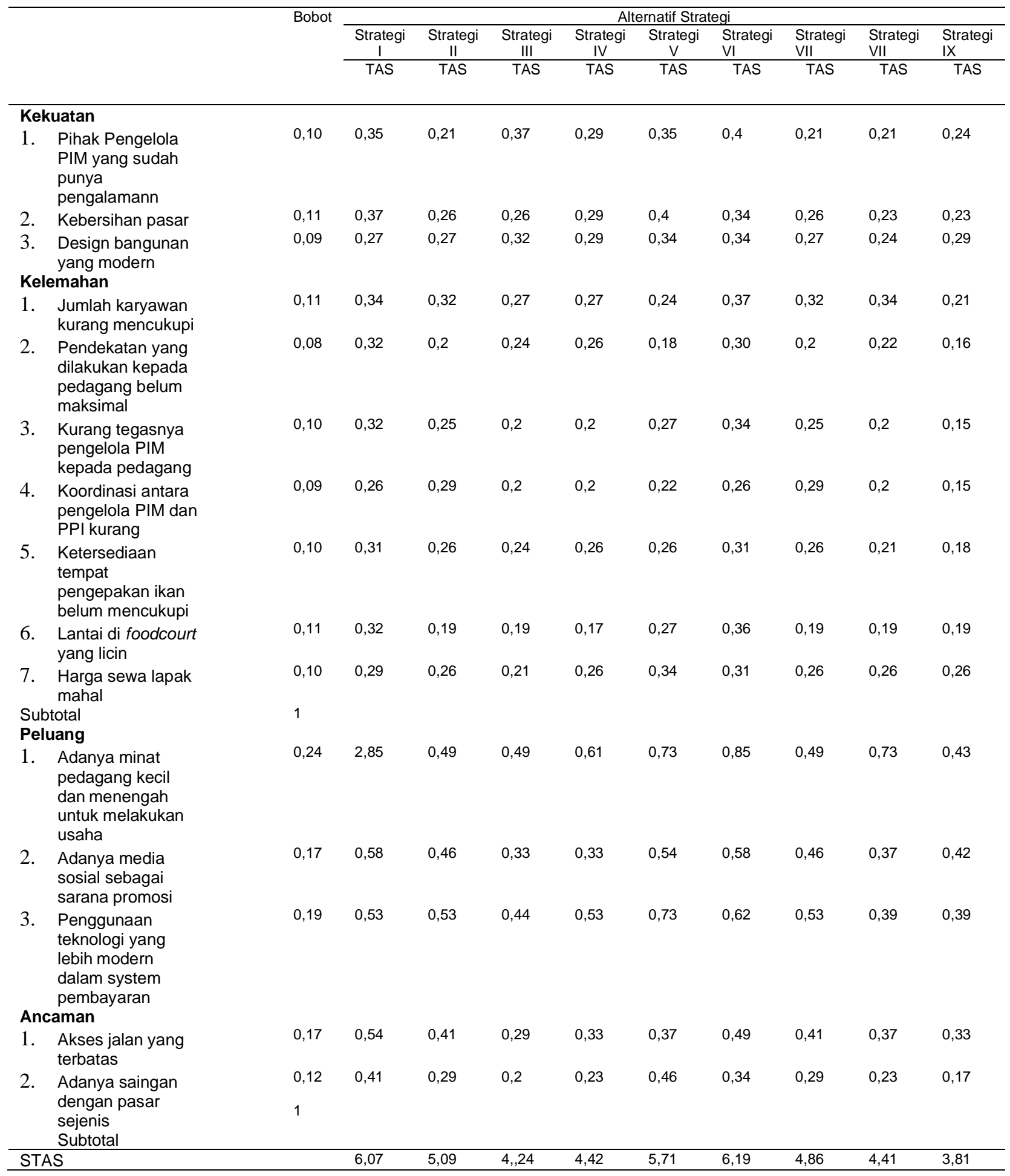

Peningkatan preferensi konsumen terhadap produk dan lingkungan pemasaran yang memperhatikan sanitasi dan higienitas, mendorong pengelola pelabuhan perikanan mengembangkan pusat pemasaran ikan modern (PIM). Pusat pemasaran tersebut tidak hanya menyediakan berbagai produk perikanan, tetapi juga memberikan kenyamanan dan jaminan mutu produk yang memadai. Salah satu PIM tersebut berlokasi di Pelabuhan Perikanan Samudera Nizam Zachman Jakarta.

Upaya yang dilakukan dengan merelokasi PPI yang merupakan pasar ikan tradisional menjadi PIM dengan konsep modern, tidak serta memberikan keuntungan kepada pengelola PIM tersebut. Hasil analisis 
pendapatan menunjukkan bahwa pendapatan PIM masih berada di bawah pendapatan PPI di masa yang lalu. Hal penting yang menjadi penyebabnya adalah relatif tingginya biaya operasional pasar. Evaluasi terhadap pendapatan suatu perusahaan perlu dilakukan agar dapat memprediksi keuntungan dan dapat dijadikan sebagai acuan pengelolaan perusahaan ke depan. Hal yang menjadi pertimbangannya disampaikan Rawis et al. (2016) bahwa laba perusahaan dapat dijadikan sebagai ukuran dari efisiensi dan efektifitas dalam sebuah unit kerja disebabkan karena tujuan utama dari pendirian perusahaan adalah memperoleh laba yang sebesar-besarnya dalam jangka pendek maupun jangka panjang. Hal ini juga terjadi karena mahalnya harga fasilitas yang disediakan para pengelola antara lain lapak, kios dan air asin serta air tawar membuat para pedagang kesulitan dalam melakukan pemenuhan pembayaran fasilitas tersebut dan menyebabkan piutang yang dimiliki PIM semakin meningkat. Calon penyewa lapak mempertimbangkan beberapa faktor sebelum menyewa lapak tersebut. Ray (2018) menjelaskan bahwa faktor lokasi dan harga sewa memberikan pengaruh yang signifikan terhadap keputusan penyewa kios. Selain itu, pengeluaran yang dihasilkan oleh pengelola PIM lebih besar dibandingkan dengan pengelola PPI. Hal tersebut disebabkan karena pengelolaan air bersih dan air asin diambil alih oleh pengelola PIM yang sebelumnya di PPI dikelola sendiri oleh para pedagang.

Berdasarkan Gambar 2 matriks SWOT yang digunakan untuk menganalisis strategi pengelolaan PIM menghasilkan sembilan rekomendasi strategi yang terdiri dari strategi SO (bekerjasama dengan youtuber dan selebgram untuk kegiatan promosi dan menciptakan sistem online market untuk dapat menjangkau konsumen di berbagai wilayah yang ada di Indonesia). Hal tersebut dilakukan untuk meningkatkan promosi PIM agar dapat menarik konsumen dari berbagai kalangan. Hal ini sesuai dengan pernyataan Kumara (2016), bahwa promosi di dalam media sosial youtuber dan instagram sangat penting dilakukan dalam mendongkrak penjualan perusahaan. Sholihah (2018) juga menyatakan bahwa instagram merupakan sosial media yang banyak digunakan oleh berbagai kalangan. Penerapan promosi dengan menggunakan kedua sosial media tersebut dapat meningkatkan ketertarikan konsumen untuk mengunjungi PIM. Penggunaan online market untuk memperluas jangkauan pasar dapat memudahkan konsumen yang berada di luar wilayah Jakarta dalam proses pemesanan. Menurut Madiani dan Imanuel (2013), menyatakan bahwa transaksi yang dilakukan secara online memberikan banyak kemudahan bagi konsumen. Penelitian Agustinah dan Widayati (2019) juga mendukung bahwa pemanfaatan media sosial berpengaruh sekitar $76,4 \%$ terhadap sarana promosi perusahaan. Berdasarkan penjelasan penjelasan tersebut dapat dikatakan bahwa pemanfaatan media sosial menjadi pilihan strategi yang harus dilakukan pengelola PIM dalam upaya meningkatkan skala usaha perusahaan. Promosi yang efektif pada akhirnya akan meningkatkan minat beli dari konsumen (Nasution dan Yasin 2017). Namun demikian, beberapa faktor yang perlu diperhatikan untuk keberhasilan usaha secara online, diantaranya yang disampaikan oleh Ratnasari (2017) yaitu modal usaha, pengalaman usaha, tingkat pendidikan dan tenaga kerja.

Strategi ST (meningkatkan ciri khas PIM dan meningkatkan kerjasama dengan pemerintah pusat). Hal tersebut dilakuan agar pemerintah pusat turut memberikan dukungan terhadap akses jalan menuju PIM agar bisa dilalui oleh kendaraan besar dari dua arah dan memberikan kesan terbaik terhadap PIM kepada konsumen. Ciri khas yang dimaksud adalah para pedagang menggunakan seragam lengkap dengan sarung tangan serta memberikan aroma pasar yang menyegarkan sehingga dapat mengurangi stigma masyarakat terhadap pasar ikan yang bau, becek dan kotor serta dapat menarik daya tarik konsumen. Selain untuk meningkatkan daya tarik konsumen, hal tersebut dapat memberikan kontribusi yang baik bagi lingkungan di sekitar PIM. Menurut Muninggar et al. (2016), PPSNZJ sudah seharusnya melakukan pengelolaan lingkungan agar semua fasilitas memenuhi standar kesehatan dan higienis dalam konsep Pelabuhan berwawasan lingkungan.

Strategi WO (memberikan sistem angsuran dalam proses pembayaran lapak dan fasilitas untuk para pedagang, pengembangan usaha kecil dan menengah, penambahan area pembongkaran ikan yang nyaman, bersih dan mudah dijangkau oleh pedagang maupun konsumen). Hal tersebut dilakukan untuk meringankan beban para pedagang terhadap kenaikan harga fasilitas yang ada di PIM sehingga menghindari keterlambatan dan penunggakan pedagang untuk melakukan proses pembayaran serta dapat memberikan kenyamanan kepada 
pedagang dalam pemakaian fasilitas yang disediakan oleh pengelola.

Strategi WT (meningkatkan spesialisasi kerja karyawan dan peningkatan pemantauan terhadap ketersediaan fasilitas PIM, melakukan koordinasi dan meningkatkan komunikasi antara pengelola PIM dan PPI, sesama pengelola PIM, serta pengelola PIM dengan pedagang). Hal ini dilakukan untuk meningkatkan koordinasi dan komunikasi antar pengelola maupun pengelola dengan pedagang dan meningkatkan efektifitas kerja pengelola.

\section{KESIMPULAN}

Pendapatan yang dihasilkan PIM berada pada posisi yang lebih rendah dibandingkan dengan pendapatan PPI. Terdapat 9 (sembilan) strategi yang diperlukan untuk meningkatkan pendapatan PIM yaitu (1) pengembangan usaha kecil dan menengah (UKM) (2) membangun kerjasama dengan youtuber dan selebgram dalam mempromosikan PIM, (3) memberikan sistem angsuran dalam proses pembayaran lapak dan fasilitas yang digunakan para pedagang, (4) menciptakan sistem online market untuk dapat menjangkau konsumen dari berbagai wilayah di Indonesia, (5) penambahan area pembongkaran ikan yang nyaman, bersih dan mudah dijangkau oleh pedagang maupun konsumen, (6) dalan sistem pembayaan konsumen kepada pedagang penambahan karyawan dan peningkatan pemantauan terhadap ketersediaan fasilitas PIM, (7) meningkatkan spesialisasi kerja karyawan dan pemantauan terhadap ketersediaan fasilitas PIM, (8) meningkatkan ciri khas PIM, (9) melakukan koordinasi dan meningkatkan komunikasi antara pengelola PIM dan PPI, sesama pengelola PIM serta antara pengelola PIM denganpedagang.

\section{SARAN}

Perlu menerapkan strategi sebagaimana yang direkomendasikan sebagai upaya peningkatan pendapatan pasar ikan modern

\section{UCAPAN TERIMA KASIH}

Ucapan terima kasih disampaikan kepada Pengelola Jurnal Teknologi dan Manajemen Perikanan Laut yang berkenan mereview dan menerbitkan tulisan ini.

\section{DAFTAR PUSTAKA}

Agustinah F, Widayati. 2019. Pemanfaatan Media Sosial sebagai Sarana Promosi Makanan Ringan Kripik Singkong di Kabupaten Sampang. Jurnal Dialektika. 4(2): 1-20.

[DJPDSPKP] Surat Keputusan Direktur Jenderal Penguatan Daya Saing Produk Kelautan dan Perikanan Nomor 130/KEP-DJPDSPKP/2018 tentang Penugasan kepada Perusahaan Umum Perikanan Indonesia sebagai Pengelola Sementara Operasionalisasi PIM Muara Baru Jakarta. Jakarta (ID): DJPDSPKP.

Endrawanti S, Wahyuningsih CD. 2014. Dampak Relokasi Pasar Studi Kasus di Pasar Sampangan Kota Semarang. Jurnal IImiah UNTAG Semarang. 3(1): 78-93.

Kumara DS. 2016. Strategi Promosi Media Sosial Youtube dan Instagram pada Produk Simcard Loop PT Telkomsel. Laporan Praktik Kerja Lapangan. Surabaya (ID): Universitas Airlangga.

Madiani IE, Imanuel OJ. 2013. Analisis Keputusan Pembelian Konsumen melalui Media Online (e-marketing). Jurnal Ekonomi. 4(2): 151-161.

Manzanaris MR, Rares JJ, Kiyai B. 2018. Dampak Kebijakan Relokasi Pasar Tradisional Rawajaya di Wilayah Kota Tobelo Kabupaten Halmahera Utara. Jurnal Administrasi Publik. 4(52): 115.

Muninggar R, Lubis E, Iskandar BH, Haluan J. 2016. Aspek Lingkungan Signifikan di Pelabuhan Perikanan Samudera Nizam Zachman Jakarta. Jurnal Teknologi dan Manajemen Perikanan Laut. 2(7): 203-210.

Nasution MFR, Yasin H. 2017. Pengaruh Promosi dan Harga terhadap Minat Beli Perumahan Obama PT Nailah Adi Kurnia Sei Mencirim Medan. Jurnal Managemen dan Bisnis. 4(2): 135-143.

Nazwirman, Wulandari E. 2016. Analsis SWOT untuk Strategi Pemasaran PT Indorama Synthetics Tbk. Journal of Economics and Business Aseanomics (JEBA). 1(1): 138-162. 
Nurdyana E, Rosyid A, Boesono H. 2013. Strategi Peningkatan Pemanfaatan Fasilitas Dasar dan Fasilitas Fungsional Pelabuhan Perikanan Pantai (PPP) Tegalsari Kota Tegal. Jurnal Resources Utilization Management and Technology. 2(2): 35-45.

[Permen KP] Peraturan Menteri Kelautan dan Perikanan Republik Indonesia no 8 tahun 2012 tentang Kepelabuhanan Perikanan. Kementerian Kelautan dan Perikanan. Jakarta.

[Perpres] Peraturan Presiden Republik Indonesia Nomor 3 Tahun 2017 Tentang Rencana Aksi Percepatan Pembangunan Industri Perikanan Nasional.

[PP] Peraturan Pemerintah Republik Indonesia Nomor 9 Tahun 2013 Tentang Perusahaan Umum (Perum) Perikanan Indonesia.

Putri AS, Solihin I, Wiyono ES, 2017. Strategi Optimalisasi Fungsi Pelabuhan Perikanan dalam Pemasaran Hasil Tangkapan di PPP Lempasing. Jurnal Teknologi dan Manajemen Perikanan Laut. 1(2): 171-183.

Sam AR, Wisudo SH, Mudiyanto B, Hascaryo B. 2011. Strategi Pengembangan Pelabuhan Perikanan Samudera Nizam Zachman Jakarta (PPSNZJ) sebagai Pusat Pemasaran Perikanan. . Jurnal Teknologi dan Manajemen Perikanan Laut. 2(2): 129-139.

Setyorini H, Effendi M, Santoso I. 2016. Analisis Strategi Pemasaran Menggunakan Matriks SWOT dan QSPM (Studi Kasus; Restoran WS Soekarno Hatta Malang). Jurnal Teknologi dan Manajemen Teknoindustri. 5(1): 46-53.

Sholihah A. 2018. Penggunaan Instagram sebagai Media Promosi (Studi Deskriptif Kualitatif pada Produk Teh Thailand Pikameame di Yogyakarta). [skripsi]. Yogyakarta (ID) : Universitas Islam Negeri Sunan Kalijaga.

Siyoto S, Sari N. 2016. Aplikasi dan Teknik Survey Bidang Kesehatan.
Yogyakarta (ID): Literasi Media Suriadi, Itta D, Yoesran M. 2015. Analisis Biaya dan Pendapatan Serta Waktu Pengembalian Modal Usaha Hasil Hutan Bukan Kayu Berupa Tanaman Hias. Jurnal Hutan Tropis. 3(3): 232-240.

Rahmawati W, Suryono A dan Siswidiyanto. 2014. Pengembangan Pelabuhan Perikanan dalam Rencana Penyerapan Tenaga Kerja Masyarakat Pesisir (Studi pada Kantor Pelabuhan Perikanan Nusantara Brondong Kabupaten Lamongan). Jurnal Administrasi Publik (JAP). 2(2): 367-373.

Rangkuti F. 2018. Teknik Membedah Kasus Bisnis (Analisis SWOT). Jakarta . PT Gramedia Pustaka Utama.

Ratnasari AD. 2017. Analisis Faktor-faktor yang Mempengaruhi Keberhasilan Usaha Bisnis Online Shop di Kota Samarinda. e-Journal Administrasi Bisnis. 5(1): 122-124.

Rawis JEO, Panelewen VVJ, Mirah AD. 2016. Analisis Keuntungan Usaha Kecil Kuliner dalam Upaya Pengembangan UMKM di Kota Manado (Studi Kasus Usaha Catering Miracle Ranotana Weru). Jurnal EMBA. 4(2): 106-119.

Ray RIW. 2018. Lokasi dan Harga Berpengaruh terhadap Keputusan Pedagang Menyewa Kios (Studi Kasus pada Pasar Kemiri Muka Kota Depok). IJPA: The Indonesian Journal of Public Administration. 4(2): 27- 48.

Revitasari E. 2017. Pengelolaan Pasar Tradisional oleh Dinas Perindustrian dan Perdagangan di Kabupaten Lebak. [skripsi]. Serang (ID): Universitas Sultan Ageng Tirtayasa

Umar H. 2008. Strategic Management in Action. Jakarta (ID): PT Gramedia Pustaka Utama Utomo TJ. 2010. Lingkungan bisnis dan persaingan bisnis ritel. Jurnal Ekonomi. 5(1): 7080.

Wagiran. (2013). Metodologi Penelitian Pendidikan (Teori dan Implementasi). Yogyakarta (ID): CV Budi Utama. 